OPEN ACCESS

Edited by:

Laigeng Li,

Institutes of Plant Physiology and

Ecology, China

Reviewed by:

Wei Zeng,

Melbourne University, Australia

John Ralph,

University of Wisconsin-Madison, USA

*Correspondence: Mirko Bunzel mirko.bunze/@kit.edu

Specialty section:

This article was submitted to

Plant Physiology,

a section of the journal

Frontiers in Plant Science

Received: 18 November 2015

Accepted: 21 December 2015

Published: 14 January 2016

Citation:

Schendel RR, Meyer MR and Bunzel M (2016) Quantitative Profiling

of Feruloylated Arabinoxylan

Side-Chains from Graminaceous Cell

Walls. Front. Plant Sci. 6:1249.

doi: 10.3389/fpls.2015.01249

\section{Quantitative Profiling of Feruloylated Arabinoxylan Side-Chains from Graminaceous Cell Walls}

\author{
Rachel R. Schendel, Marleen R. Meyer and Mirko Bunzel*
}

Department of Food Chemistry and Phytochemistry, Institute of Applied Biosciences, Karlsruhe Institute of Technology, Karlsruhe, Germany

Graminaceous arabinoxylans are distinguished by decoration with feruloylated monosaccharidic and oligosaccharidic side-chains. Although it is hypothesized that structural complexity and abundance of these feruloylated arabinoxylan side-chains may contribute, among other factors, to resistance of plant cell walls to enzymatic degradation, quantitative profiling approaches for these structural units in plant cell wall materials have not been described yet. Here we report the development and application of a rapid and robust method enabling the quantitative comparison of feruloylated side-chain profiles in cell wall materials following mildly acidic hydrolysis, C18-solid phase extraction (SPE), reduction under aprotic conditions, and liquid chromatography with diode-array detection/mass spectrometry (LC-DAD/MS) separation and detection. The method was applied to the insoluble fiber/cell wall materials isolated from 12 whole grains: wild rice (Zizania aquatica L.), long-grain brown rice (Oryza sativa L.), rye (Secale cereale L.), kamut (Triticum turanicum Jakubz.), wheat (Triticum aestivum L.), spelt (Triticum spelta L.), intermediate wheatgrass (Thinopyrum intermedium), maize (Zea mays L.), popcorn (Zea mays L. var. everta), oat (Avena sativa L.) (dehulled), barley (Hordeum vulgare L.) (dehulled), and proso millet (Panicum miliaceum L.). Between 51 and 96\% of the total esterified monomeric ferulates were represented in the quantified compounds captured in the feruloylated side-chain profiles, which confirms the significance of these structures to the global arabinoxylan structure in terms of quantity. The method provided new structural insights into cereal grain arabinoxylans, in particular, that the structural moiety $\alpha$-L-galactopyranosyl(1 $\rightarrow 2$ )- $\beta$-D-xylopyranosyl-(1 $\rightarrow 2)$-5-O-trans-feruloyl-L-arabinofuranose (FAXG), which had previously only been described in maize, is ubiquitous to cereal grains.

Keywords: plant cell walls, cereal grains, feruloylated oligosaccharides, arabinoxylans, screening, ferulic acid, arabinoxylan side-chains

Abbreviations: FA, 5-O-trans-feruloyl-L-arabinofuranose; FAX, $\quad \beta$-D-xylopyranosyl-(1 $\rightarrow 2)-5$-O-(trans-feruloyl)-Larabinofuranose; FAXG, $\alpha$-L-galactopyranosyl-( $1 \rightarrow 2)-\beta$-D-xylopyranosyl-(1 $\rightarrow 2)-5$-O-trans-feruloyl-L-arabinofuranose; FAXGG, $\quad \alpha$-D-galactopyranosyl-( $1 \rightarrow 3)$ - $\alpha$-L-galactopyranosyl-(1 $\rightarrow 2)-\beta$-D-xylopyranosyl-(1 $\rightarrow 2)-5$-O-trans-feruloyl-Larabinofuranose; FAXGX, $\alpha$-D-xylopyranosyl-( $1 \rightarrow 3)-\alpha$-L-galactopyranosyl- $(1 \rightarrow 2)-\beta$-D-xylopyranosyl-( $1 \rightarrow 2)-5$-O-transferuloyl-L-arabinofuranose; LOD, limit of detection; LOQ, limit of quantification; SPE, solid phase extraction; TFA, trifluoroacetic acid. 


\section{INTRODUCTION}

Ferulic acid is found ester-linked to arabinoxylans in the primary and secondary cell walls of grasses. These feruloylated arabinoxylans are a distinguishing feature of grass cell walls and represent their principal hemicellulosic component, making up 20-40 and 40-50\%, respectively, of primary and secondary grass cell walls on a dry weight basis (Vogel, 2008). However, feruloylated arabinoxylans are not limited to the Poaceae family, but are found in the primary cell walls of all commelinid monocotyledons (Harris and Trethewey, 2010).

All feruloylated arabinoxylans are based on a $(1 \rightarrow 4)$-linked $\beta$-D-xylopyranosyl backbone structure decorated with various substituents. $\alpha$-L-arabinofuranose dominates the substitution landscape as either a mono- and/or di-substituent at the xylopyranosyl $O-3$ and/or $O-2$ positions, but additional backbone decorations such as glucuronic acid, its 4-O-methyl derivative, or acetyl are also observed, particularly in maize and sorghum arabinoxylans (Verbruggen et al., 1995; Huisman et al., 2000; Kabel et al., 2002; Appeldoorn et al., 2010, 2013). The acylation of a portion of the arabinose substituents at their O-5 position by phenolic acids, particularly trans-ferulic acid, is a key feature of arabinoxylans. Some of the ferulate residues undergo free radical-induced oxidative coupling to form ferulate dimers and higher oligomers, thus creating inter- and intramolecular cross-links between arabinoxylan chains; ferulate and diferulate coupling with lignin monomers and oligomers also results in arabinoxylan-lignin cross-linkages (Ralph et al., 1994, 1995; Saulnier et al., 1999; Allerdings et al., 2005; Bunzel et al., 2008). Arabinoxylan cross-linking is important for both plant physiological processes and utilization of graminaceous cell walls. In the plant, cross-linking is suggested to be involved in cessation of cell extension by increasing the cell wall's stiffness (Kamisaka et al., 1990), thus also improving plants' disease and insect resistance (de O Buanafina, 2009; de $\mathrm{O}$ Buanafina and Fescemyer, 2012). Increased ferulate cross-linking in plant materials enhances their resistance to enzymatic degradation, thus decreasing the digestibility of forages for livestock and impeding breakdown of forage and grain byproduct materials during second-generation biofuel production (Grabber et al., 1998; Chundawat et al., 2011; Jung et al., 2012).

In insoluble fiber from cereal grains, the molar percentage of total diferulates as percentage of the sum of monomeric and dimeric ferulates ranges between 26\% (spelt) and $45 \%$ (oats) (Bunzel, 2001). Therefore, a substantial portion of the total ferulates in grasses remains in monomeric form as feruloylated side-chains. In addition to the ubiquitous 5-O-trans-feruloyl-L--arabinofuranose (FA) structure, some grasses produce more complex, oligosaccharidic feruloylated side-chains. The feruloylated disaccharide, $\beta$-D-xylopyranosyl$(1 \rightarrow 2)$-5-O-(trans-feruloyl)-L-arabinofuranose (FAX) has been identified in the leaves of various grasses (Wende and Fry, 1997) as well as rye, maize, wild rice, and intermediate wheat grass grains (Saulnier et al., 1995; Bunzel et al., 2002; Steinhart and Bunzel, 2003; Schendel et al., 2015). In maize grain, substantial amounts of the feruloylated trisaccharide, $\alpha-\mathrm{L}-$ galactopyranosyl-( $1 \rightarrow 2)-\beta$-D-xylopyranosyl- $(1 \rightarrow 2)-5$-O-transferuloyl-L-arabinofuranose (FAXG), and smaller amounts of two feruloylated tetrasaccharides, $\alpha$-D-galactopyranosyl- $(1 \rightarrow 3)-\alpha-\mathrm{L}-$ galactopyranosyl- $(1 \rightarrow 2)-\beta$-D-xylopyranosyl- $(1 \rightarrow 2)-5$-O-transferuloyl-L-arabinofuranose (FAXGG), and $\alpha$-D-xylopyranosyl$(1 \rightarrow 3)$ - $\alpha$-L-galactopyranosyl- $(1 \rightarrow 2)-\beta$-D-xylopyranosyl- $(1 \rightarrow 2)$ 5-O-trans-feruloyl-L-arabinofuranose (FAXGX) were detected following preparative isolation (Saulnier et al., 1995; Allerdings et al., 2006).

Although the effects of these monomeric ferulate sidechains have not been as thoroughly researched as ferulate crosslinking, both increased appearance and complexity of feruloylated side-chains are hypothesized to reduce enzymatic digestibility and slow fermentation of feruloylated arabinoxylans (Yang et al., 2013; de Vries et al., 2014; Snelders et al., 2014), which has implications for plant protection mechanisms against pathogens, the prebiotic and (potential) antioxidative human health benefits of dietary fibers from different cereal grains, livestock nutrition, and biofuel production. However, to date, a direct quantitative comparison of the feruloylated side-chain profiles from different grain or forage materials has not been performed, and estimations of profile complexity have been based on results from time-consuming preparative isolations (Saulnier et al., 1995; Bunzel et al., 2002; Allerdings et al., 2006). We have, therefore, developed a liquid chromatography with diode-array detection/mass spectrometry (LC-DAD/MS) screening method enabling quantitative comparison of the feruloylated side-chain profiles of plant cell wall materials following mildly acidic hydrolysis, C18-solid phase extraction (SPE), and reduction.

\section{MATERIALS AND METHODS}

\section{Chemicals}

Trifluoroacetic acid (TFA) and sodium borohydride were from Sigma (Seelze, Germany). Trans-ferulic acid was from Fluka (Buchs, Switzerland). DMSO was from Roth (Karlsruhe, Germany). All chromatography solvents (MS grade) were from VWR (Bruchsal, Germany). Water was deionized and filtered through a Milli-Q Reference water purification system (Merck Millipore, Billerica, Massachusetts, USA).

\section{Plant Materials and Enzymes}

Cellulose was from Roth, xylans (from beechwood) were purchased from Sigma. Maize (Zea mays L.) middlings were a gift from Cornexo $\mathrm{GmbH}$ (Freimersheim, Germany). Intermediate wheatgrass (Thinopyrum intermedium) grain was kindly shared by Dr. Lee DeHaan from The Land Institute, Salina, Kansas, USA. Wholegrain maize flour (Zea mays L.) was a gift from Mühle Beck (Keltern, Germany). Wild rice (Zizania aquatica L.), longgrain brown rice (Oryza sativa L.), rye (Secale cereale L.), kamut (Triticum turanicum Jakubz.), wheat (Triticum aestivum L.), spelt (Triticum spelta L.), popcorn (Zea mays L. var. everta), oat (Avena sativa L.) (dehulled), barley (Hordeum vulgare L.) (dehulled), and proso millet (Panicum miliaceum L.) whole grains were purchased from local grocery stores. Thermostable $\alpha$-amylase (Termamyl $120 \mathrm{~L}$ ), amyloglucosidase (AMG $300 \mathrm{~L}$ ), and protease 
<smiles>COc1cc(/C=C/C(=O)OC2OC3C(O)OC2C3O)ccc1O</smiles>

I. FA

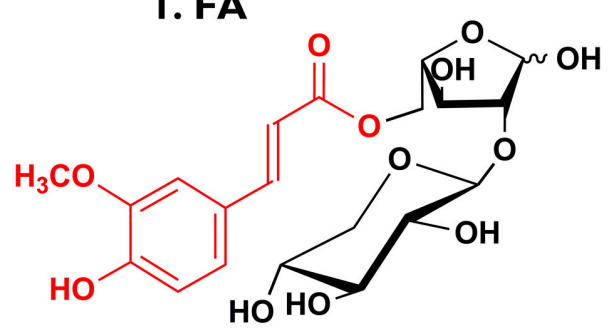

2. FAX

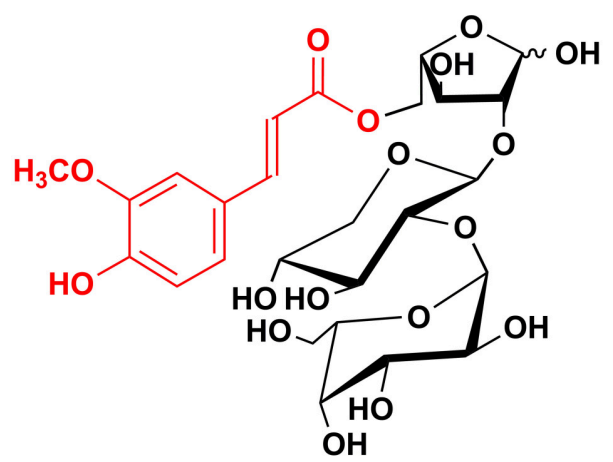

3. FAXG

FIGURE 1 | Feruloylated arabinoxylan side-chain standard compounds isolated from insoluble maize fiber in preparative quantities. (1) FA, 5-O-trans-feruloyl-L-arabinofuranose; (2) FAX, $\beta$-D-xylopyranosyl-(1 $\rightarrow 2$ )5-O-(trans-feruloyl)-L-arabinofuranose; (3) FAXG, $\alpha$-L-galactopyranosyl$(1 \rightarrow 2)-\beta$-D-xylopyranosyl-( $1 \rightarrow 2)-5$-O-trans-feruloyl-L-arabinofuranose.

(Alcalase 1.5 MG Type FG) for preparative fiber isolation were kind gifts from Novozymes (Bagsvaerd, Denmark).

\section{General}

SPE cartridges (Chromabond C18, $500 \mathrm{mg}, 3 \mathrm{~mL}$ ) were from Macherey-Nagel (Düren, Germany). Amberlite XAD-2 column material was from Supelco (Bellafonte, Pennsylvania, USA). Sephadex LH-20 material was from Sigma.

\section{Isolation of Insoluble Fiber Material}

All grain materials were ground to $<0.5 \mathrm{~mm}$ (IKA MF10 Basic mill, Staufen, Germany) and partially de-fatted by washing with acetone. Insoluble fiber was isolated in triplicate (except for maize middlings, where the isolated material was pooled into one sample) from each of the grain materials in preparative quantities as described by Bunzel et al. (2001) with minor modifications. Briefly, for each triplicate sample $20 \mathrm{~g}$ of defatted flour was mixed with $200 \mathrm{~mL}$ of sodium phosphate buffer $(0.08 \mathrm{M}, \mathrm{pH} 6.2)$ and $1.5 \mathrm{~mL}$ of thermostable $\alpha$-amylase in a $500 \mathrm{~mL}$ Erlenmeyer flask and incubated at $92^{\circ} \mathrm{C}$ for $20 \mathrm{~min}$ (flasks were swirled every $5 \mathrm{~min}$ ). The suspension was cooled to room temperature, adjusted to $\mathrm{pH} 7.5$ with $0.275 \mathrm{M}$ aqueous $\mathrm{NaOH}$ solution, and incubated with protease $(700 \mu \mathrm{L})$ for $30 \mathrm{~min}$ at $60^{\circ} \mathrm{C}$ in a shaking water bath. The suspension was cooled to room temperature, adjusted to $\mathrm{pH} 4.5$ with $0.325 \mathrm{M}$ aqueous $\mathrm{HCl}$ solution, and incubated with $700 \mu \mathrm{L}$ of amyloglucosidase for $30 \mathrm{~min}$ at $60^{\circ} \mathrm{C}$ in a shaking water bath. The warm suspensions were centrifuged $(5 \mathrm{~min}, 5000 \times g)$, the supernatant was decanted, and the insoluble residue was washed with warm water $\left(60^{\circ} \mathrm{C}, 2 \times 100 \mathrm{~mL}, 1 \times 50 \mathrm{~mL}\right)$, ethanol $(1 \times 100 \mathrm{~mL}, 1 \times 50 \mathrm{~mL})$, and acetone $(1 \times 100 \mathrm{~mL}$, $1 \times 50 \mathrm{~mL}$ ). Washed residues were dried in a vacuum oven at $70^{\circ} \mathrm{C}$ for $20 \mathrm{~h}$ and stored in a desiccator until use. Each triplicate was individually corrected for residual protein and ash. Protein content was determined as total Kjeldahl nitrogen $(\mathrm{N} \times$ 6.25) using the colorimetric method developed by Willis et al. (1996). Ash content was determined by incineration at $525^{\circ} \mathrm{C}$ for $11 \mathrm{~h}$.

\section{Preparation of Standard Compounds FA, FAX, and FAXG}

FA, FAX, and FAXG (see Figure 1) were isolated in preparative quantities from insoluble fiber from maize middlings using a modified version of the method from Allerdings et al. (2006). Briefly, $20 \mathrm{~g}$ of insoluble fiber was hydrolyzed under mildly acidic conditions $[400 \mathrm{~mL}$ of $0.05 \mathrm{M}$ trifluoroacetic acid, $\left.3 \mathrm{~h}, 100^{\circ} \mathrm{C}\right]$. The supernatant containing the released feruloylated oligosaccharides was applied to a glass column $(25 \times$ $4 \mathrm{~cm}$ ) filled with Amberlite XAD-2 material. Non-feruloylated oligosaccharides were washed from the column with water $(600 \mathrm{~mL})$, and feruloylated oligosaccharides were eluted with $\mathrm{MeOH}-\mathrm{H}_{2} \mathrm{O}(600 \mathrm{~mL}, 50 / 50, \mathrm{v} / \mathrm{v})$. A moderate elution rate was maintained (3-5 mL/min). The $\mathrm{MeOH}-\mathrm{H}_{2} \mathrm{O}$ eluate, which contains the majority of the feruloylated oligosaccharides, was concentrated under vacuum with a rotary evaporator to $10 \mathrm{~mL}$. This concentrate was directly injected (injection loop volume of $10 \mathrm{~mL}$ ) on to a Sephadex LH-20 gel chromatography column $(100 \times 2.5 \mathrm{~cm})$ using $100 \%$ water as the eluent $(1 \mathrm{~mL} / \mathrm{min}$, Jasco 880 pump, Easton, Maryland, USA). The column eluate was monitored using UV absorption (355 nm, K2600 UV detector, Knauer, Berlin Germany), and fractions were collected at 6min intervals (FC 204 fraction collector, Gilson, Middleton, Wisconsin, USA), pooled based on detected peaks, and concentrated under vacuum with a rotary evaporator. The pooled fractions corresponding to FA, FAX, and FAXG (Sephadex LH-20 retention times of 2100-2600 $\mathrm{min}, 1550-1830 \mathrm{~min}$, and 950-1120 min, respectively) were purified on a preparative RP-C18 column $(250 \times 25 \mathrm{~mm}, 5 \mu \mathrm{m}, 100 \AA$, Phenomenex, Aschaffenburg, Germany) using a preparative HPLC system consisting of two LC-8A pumps and a SPD-20A UV-Vis detector (325 nm, Shimadzu, Duisburg, Germany). The following binary gradient was used (eluent $\mathrm{A}=$ water $+0.1 \%$ formic acid, eluent $\mathrm{B}=\mathrm{MeOH}$ ): initially $75 \% \mathrm{~A}, 25 \% \mathrm{~B}$; linear over $5 \mathrm{~min}$ 
to $30 \% \mathrm{~B}$, linear over $20 \mathrm{~min}$ to $38 \% \mathrm{~B}$, linear over $5 \mathrm{~min}$ to $100 \% \mathrm{~B}$, hold for two $\mathrm{min}$, linear over $1 \mathrm{~min}$ to $25 \% \mathrm{~B}$, and re-equilibration for $7 \mathrm{~min}$. Flow rate was $8 \mathrm{~mL} / \mathrm{min}$, and fractions were collected manually. Purity of the isolated standard compounds was confirmed by $1 \mathrm{D}-\left({ }^{1} \mathrm{H}\right)$ and $2 \mathrm{D}-\mathrm{NMR}\left({ }^{1} \mathrm{H}-\right.$ ${ }^{1} \mathrm{H}$-COSY, HSQC, and HMBC) experiments at $298 \mathrm{~K}$ using an Ascend $500 \mathrm{MHz}$ spectrometer (Bruker, Rheinstetten, Germany) with a Prodigy cryoprobe. For NMR analysis, 5-10 mg of samples were deuterium-exchanged twice and dissolved in $\mathrm{D}_{2} \mathrm{O}$, with acetone $(0.5 \mu \mathrm{L})$ as reference $\left(\delta^{1} \mathrm{H} 2.22, \delta^{13} \mathrm{C} 30.89\right.$; (Gottlieb et al., 1997)). Standard compounds were dried by lyophilization and stored at $-20^{\circ} \mathrm{C}$.

\section{Quantitative Comparison of Feruloylated Side-Chain Profiles of Plant Cell Wall Materials \\ Selective Release of Side-Chains by Mildly Acidic Hydrolysis}

Insoluble fiber materials were hydrolyzed in triplicate under the conditions described by Saulnier et al. (1995) for optimal sidechain release. Insoluble fiber material (200 mg; $100 \mathrm{mg}$ may also be used for samples with high side-chain concentrations, for example, maize-based materials) was weighed into a $15-\mathrm{mL}$ Pyrex tube, suspended in $5 \mathrm{~mL}$ of $50 \mathrm{mM}$ TFA, capped, vortexed, and incubated for $2 \mathrm{~h}$ at $100^{\circ} \mathrm{C}$ while protected from light. The samples were cooled on ice and centrifuged $(10 \mathrm{~min}, 2000 \times \mathrm{g})$. An aliquot $(3 \mathrm{~mL}$ for most samples, $3.5 \mathrm{~mL}$ for spelt, $1.5 \mathrm{~mL}$ for maize and popcorn) of the supernatant was cleaned up using C18 SPE cartridges. The cartridges were washed with $\mathrm{MeOH}$ $(6 \mathrm{~mL})$ and re-conditioned with water $(6 \mathrm{~mL})$ before application of the hydrolysate aliquot. The loaded cartridge was washed with water $(6 \mathrm{~mL})$, and the feruloylated side-chains were eluted with $\mathrm{MeOH}(6 \mathrm{~mL})$ into a small Pyrex tube $(15 \mathrm{~mL})$. The solutions were evaporated with a rotary evaporator (maximum water bath temperature of $45^{\circ} \mathrm{C}$ ); residual water was removed in a vacuum drying oven at $40^{\circ} \mathrm{C}$.

\section{Reduction}

The isolated side-chains in the dried residues were reduced to their corresponding sugar alcohols with $\mathrm{NaBH}_{4}$ in DMSO ( $2 \mathrm{~mL}, 30 \mathrm{mg} \mathrm{NaBH}_{4} / \mathrm{mL}$ DMSO, solution freshly prepared by sonicating in a sealed Pyrex glass at $45^{\circ} \mathrm{C}$ ) for $18 \mathrm{~h}$ at $30^{\circ} \mathrm{C}$ with stirring [in tightly sealed small Pyrex tubes $(15 \mathrm{~mL})$ ]. Samples were protected from light to prevent cis/trans isomerization. The reaction was stopped with the rapid dropwise addition of $2 \mathrm{~mL}$ of $1 \mathrm{M}$ aqueous $\mathrm{HCl}$. (Caution: plant hydrolysate samples may foam significantly at this step). Samples were directly analyzed with LC-DAD/MS or, if necessary, diluted with 50/50 DMSO/ $\mathrm{H}_{2} \mathrm{O}$ $(\mathrm{v} / \mathrm{v})$.

\section{LC-DAD/MS Analysis}

The reduced samples were analyzed on a Thermo Scientific (Waltham, Massachusetts, USA) system consisting of a Finnigan Surveyor Plus autosampler, pump, and photodiode array detector, and an LXQ-Triple Quad ion trap $\mathrm{MS}^{\mathrm{n}}$ detector. $25 \mu \mathrm{L}$ of the sample was separated at room temperature on a Luna C18 column $(250 \times 4.6 \mathrm{~mm}, 5 \mu \mathrm{M}$ particle size $)$ from Phenomenex
(Aschaffenburg, Germany) using a $0.5 \mathrm{~mL} / \mathrm{min}$ flow rate and a binary gradient made up of water with $0.1 \%$ formic acid (eluent A) and acetonitrile with $0.1 \%$ formic acid (eluent B). The initial gradient conditions were $95 \% \mathrm{~A}, 5 \% \mathrm{~B}$; hold for $4 \mathrm{~min}$; B from 5 to $10 \%$ in $4 \mathrm{~min}$; hold for $2 \mathrm{~min}$; B from 10 to $16 \%$ in $4 \mathrm{~min}$; hold for $9 \mathrm{~min}$; B from 16 to $50 \%$ in $10 \mathrm{~min}$; B from 50 to $95 \%$ in $1 \mathrm{~min}$; hold for $2 \mathrm{~min}$; B from 95 to $5 \%$ in $1 \mathrm{~min}$; re-equilibrate for $5 \mathrm{~min}$. The eluate was monitored at $325 \mathrm{~nm}$ on the photodiode array detector. Ionization for the MS system was performed in the ESI positive mode, capillary temperature was $350^{\circ} \mathrm{C}$, spray voltage was $4 \mathrm{kV}$, and capillary voltage was $47 \mathrm{~V}$.

\section{Quantification of FA, FAX, FAXG, and Free Ferulic Acid}

External calibration curves were prepared in triplicate for FA, FAX, and FAXG by weighing in appropriate amounts of the dried standard compounds, dissolving in $\mathrm{MeOH}$ and diluting as necessary. Aliquots of increasing volume were pipetted from the respective triplicate stock solutions into 15-mL Pyrex tubes to create equidistant, five-point calibration curves, dried down, reduced using the method described above (except the volumes of the $\mathrm{NaBH}_{4}$ in DMSO and $1 \mathrm{M} \mathrm{HCl}$ solutions were both reduced to $1 \mathrm{~mL}$ ), and analyzed using the LC-DAD/MS method (quantification performed via UV-absorbance at $325 \mathrm{~nm}$; ESI-MS and MS/MS used for confirmation of peak identity) described above. The concentration range of the FA calibration curve was $10-260 \mu \mathrm{M}$, and FAX and FAXG were calibrated from 6 to $26 \mu \mathrm{M}$. Free ferulic acid released during the TFA hydrolysis was quantified by preparing stock solutions of trans-ferulic acid in triplicate in $\mathrm{MeOH} / \mathrm{H}_{2} \mathrm{O}(50 / 50, \mathrm{v} / \mathrm{v})$ and diluting appropriately to create six-point calibration curves (calibration range: 6$25 \mu \mathrm{M})$.

\section{Method Validation}

Limits of detection (LOD) and limits of quantification (LOQ) were calculated as signal-to-noise ratios of $3: 1$ and 9:1, respectively. Linearity was assessed by inspecting the residual plots and correlation coefficients. Robustness of the quantification method for FA, FAX, and FAXG was tested by preparing six separate calibration curves (each originating from separate stock solutions) for each compound at different times (three calibration curves for each compound were prepared at the same time as a set, with four months' time between the first and second set). Percent recovery from the SPE and reduction steps in the method was calculated by drying down aliquots of FA, FAX, and FAXG in triplicate. The residues were dissolved in $100 \mu \mathrm{L}$ of DMSO, and mixed with $3 \mathrm{~mL}$ of hydrolysate from a 1:1 $(\mathrm{w}: \mathrm{w})$ mixture of cellulose and beechwood xylan subjected to the mildly acidic degradation method described. This mixture was then carried through SPE-cleanup, reduction, and LC-DAD/MS analysis.

\section{Total Ester-Linked trans-Ferulic Acid Analysis}

The total ester-linked trans-ferulic acid in all insoluble fiber materials except for intermediate wheatgrass was determined according to Dobberstein and Bunzel (2010), with slight 
modifications. The method used for quantification of transferulic acid in intermediate wheat grass was very similar (see (Schendel et al., 2015) for an exact description). 25-50 mg (with the exception of insoluble fiber from oats, where $100 \mathrm{mg}$ was used) of insoluble fiber material from each of the sample triplicates was weighed in, and ortho-coumaric acid ( $5 \mathrm{mM}$ stock solution, prepared in $\mathrm{MeOH} / \mathrm{H}_{2} \mathrm{O}(50 / 50, \mathrm{v} / \mathrm{v})$ ) was added as an internal standard in the appropriate volume to create a concentration of $250 \mu \mathrm{M}$ in the end samples. The samples were stirred with $5 \mathrm{~mL}$ of $2 \mathrm{M} \mathrm{NaOH}$ for $18 \mathrm{~h}$ at room temperature in the dark, acidified to $\mathrm{pH} 2$ with $\approx 1 \mathrm{~mL} 37 \% \mathrm{HCl}$, and extracted with diethyl ether $(3 \times, 8,6$, and $4 \mathrm{~mL})$. The ether volumes were combined, dried under $\mathrm{N}_{2}$, dissolved in $\mathrm{MeOH} / \mathrm{H}_{2} \mathrm{O}(50 / 50$, $\mathrm{v} / \mathrm{v}$ ), and analyzed with a Shimadzu (Duisburg, Germany) HPLCDAD system consisting of three LC-20AT pumps and a DGU20A3 degasser, SIL-20AC autosampler, CTO-20AC column oven, and SPD-M20A diode array detector. Samples were separated on a Phenomenex Luna phenyl-hexyl column $(250 \times 4.6 \mathrm{~mm}, 5 \mu \mathrm{M}$ particle size) using a tertiary gradient made up of $1 \mathrm{mM}$ TFA in water (eluent A); acetonitrile/1 mM TFA in water, 90/10, v/v (eluent B); and $\mathrm{MeOH} / 1 \mathrm{mM}$ TFA in water, 90/10, v/v (eluent C). The gradient was performed as follows: initial conditions, $87 \% \mathrm{~A}, 13 \% \mathrm{~B}$; hold for $11 \mathrm{~min}$; B from 13 to $15 \%$ in $12 \mathrm{~min}$; B from 15 to $16 \%$ in $5 \mathrm{~min}$; B from 16 to $50 \%$ and C from 0 to $25 \%$ in $4 \mathrm{~min}$; B from 50 to $13 \%$, and C from 25 to $0 \%$ in $1 \mathrm{~min}$; followed by a re-equilibration step. Injection volume was $10 \mu \mathrm{L}$, and flow rate was $1 \mathrm{~mL} / \mathrm{min}$. Quantification was performed at $325 \mathrm{~nm}$ with a linear, 12 -point internal calibration curve prepared for trans-ferulic acid (concentration range: 5-2500 $\mu \mathrm{M}$ ), using ortho-coumaric acid as the internal standard (concentration: $250 \mu \mathrm{M})$.

\section{RESULTS}

\section{Quantitative Screening of Feruloylated Side-Chain Profiles: Reduction Method Development}

The reducing sugar moiety of the native standard compounds rules out their chromatographic separation under the primarily aqueous conditions applied in C18-based HPLC, where oncolumn mutarotation between the reducing sugar's $\alpha$ - and $\beta$ anomers, which differ slightly in their retention factors, produces broad, tailing, split peaks (see Figure 2A). This was especially true for FAX, which spawned a peak over 4 min wide. Reduction of the standard compounds to sugar alcohols with sodium borohydride in the aprotic solvent DMSO resulted in sharp, baseline-separated peaks, including separation of the cis- and trans-isomers of each compound (see Figure 2B, which depicts a chromatogram from a mixture of cis- and trans-isomers).

Several challenges were encountered during development of the reduction method. The first, the appearance of additional peaks in the chromatogram with the same mass-to-charge ratio $(\mathrm{m} / \mathrm{z})$ as the reduced standard compounds (see Figure 2C), arose when the reduction was performed in a protic solvent (for example, $\mathrm{MeOH}$, EtOH, or DMSO- $\mathrm{H}_{2} \mathrm{O}$ mixtures). This behavior was attributed to a base-catalyzed Lobry de Bruyn-van

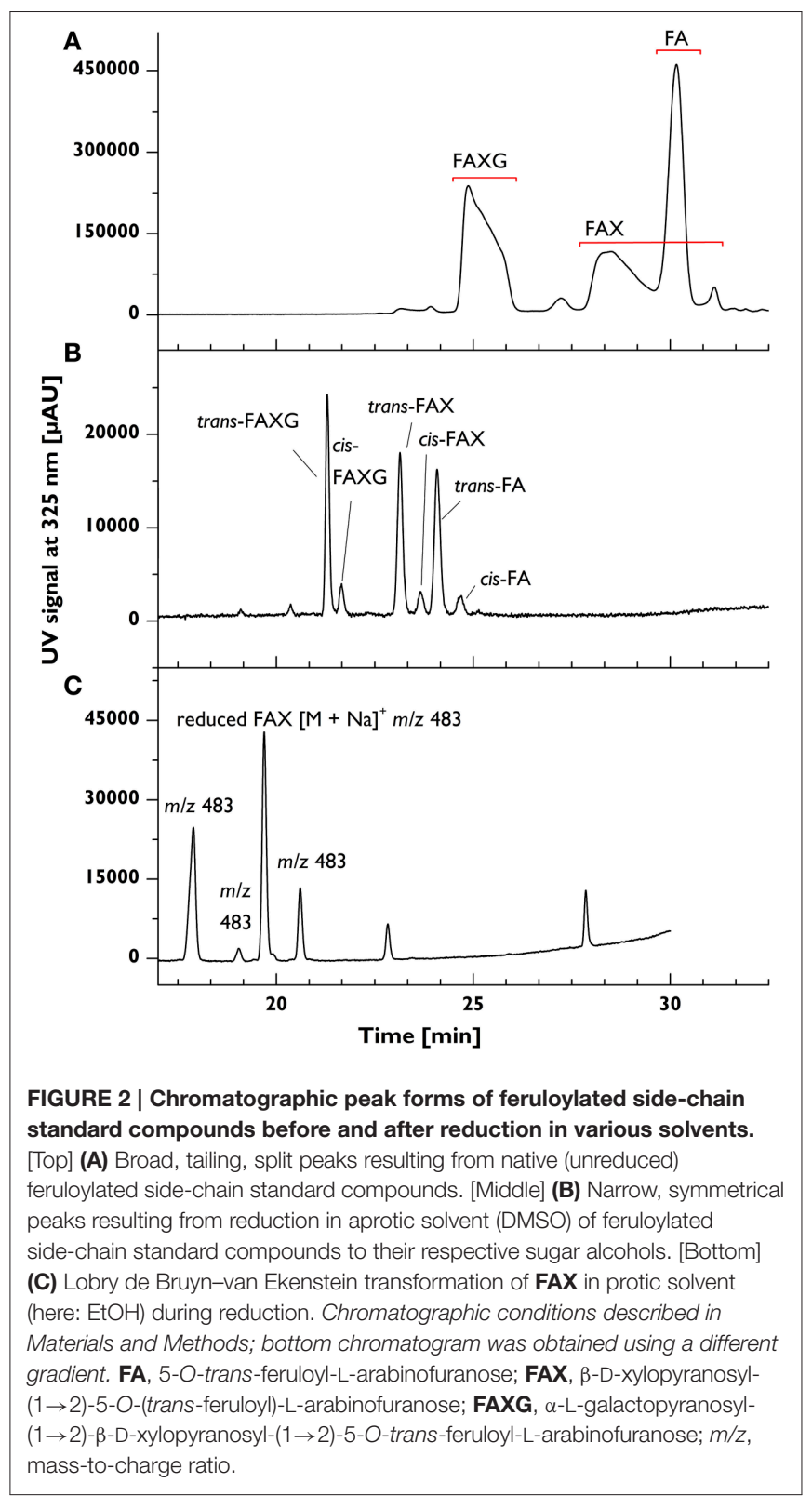

Ekenstein transformation of the reducing arabinose to other sugars via an enediol reaction intermediate. The use of DMSO, an aprotic solvent, resulted in one chromatographic peak per standard compound. Nevertheless, care must still be taken during the reduction to avoid accidentally introducing water into the system. Both DMSO and sodium borohydride are strongly hygroscopic, so the reducing solution should be freshly prepared in a sealed container and the individual samples should be tightly sealed during reduction. Additionally, the $\mathrm{HCl}$ workup at the end of reduction should be performed as quickly as feasible without allowing the sample to foam over: excessive time spent in completing the acid addition creates a temporarily alkaline, protic environment, which facilitates the transformation reaction. 


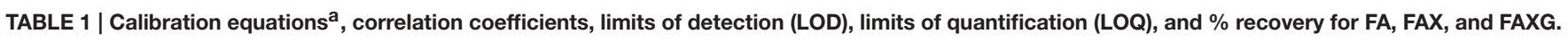

\begin{tabular}{|c|c|c|c|c|c|c|}
\hline & Range tested $(\mu \mathrm{M})$ & Linear calibration equation & Correlation coefficients & LOD $(\mu \mathrm{M})$ & $\operatorname{LOQ}(\mu \mathrm{M})$ & Recovery $(\% \pm \mathrm{SD})^{\mathrm{b}}$ \\
\hline FA & $10-260$ & $y=26806 x-190178$ & 0.9812 & 1.4 & 4.2 & $93.5 \pm 5.8$ \\
\hline FAX & $6-26$ & $y=33194 x-29998$ & 0.9607 & 0.8 & 2.4 & $98.7 \pm 7.8$ \\
\hline FAXG & $6-26$ & $y=37649 x-37727$ & 0.9813 & 0.6 & 1.8 & $93.4 \pm 5.3$ \\
\hline
\end{tabular}

${ }^{a}$ Calibration equations and correlation coefficients were calculated from three separate calibrations.

${ }^{b} n=3$. FA, 5-O-trans-feruloyl-L-arabinofuranose; FAX, $\beta$-D-xylopyranosyl-(1 $\left.\rightarrow 2\right)$-5-O-(trans-feruloyl)-L-arabinofuranose.

FAXG, $\alpha$-L-galactopyranosyl-(1 $\rightarrow 2)-\beta$-D-xylopyranosyl-(1 $\rightarrow 2)$-5-O-trans-feruloyl-L-arabinofuranose; SD, standard deviation.

A second, sporadically occurring, hurdle in reduction method development was incomplete reduction, especially with the standard compound $\mathbf{F A}$, over a range of reduction times and sodium borohydride concentrations. The final reduction conditions were chosen because the incidence of incomplete reduction was decreased, although not entirely eliminated. However, when occurring, the maximum amount of unreduced FA represented only $\approx 5 \%$ of the total FA in the samples and may, therefore, be neglected.

\section{Method Validation Results}

Table 1 summarizes the validation parameters for FA, FAX, and FAXG. Because of FAXG's especially sharp peak form, its LOD and LOQ were slightly lower than those of FAX and FA, but all three compounds displayed LOQs in the single-digit micromolar range. The recoveries for all three compounds were above $93 \%$. The robustness of the method, as shown by its reproducibility over time is illustrated in Figure 3, which depicts the linearity of six separate calibration curves prepared and analyzed 4 months apart, with each calibration curve originating from an individual stock solution. The possibility of quantifying feruloylated side-chains via a ferulic acid standard curve was tested and rejected because the free acid UV response was greater per mole than those of the feruloylated standard compounds (see Supplementary Figures 1-3). This produces the practical limitation of needing to initially isolate the standard compounds for accurate quantification. Nevertheless, the method offers a sensitive, reproducible, accurate possibility for quantification of the major feruloylated arabinoxylan side-chain compounds found in grass cell walls.

\section{MS/MS Fragmentation}

MS/MS fragmentation of the sodium adducts of the reduced standard compounds FA, FAX, and FAXG produced characteristic daughter fragments (see Supplementary Figures 4-6). Fragmentation of the sodium adduct of reduced FA ([M + $\mathrm{Na}]^{+} m / z$ 351) resulted in an $m / z 333$ daughter ion, which represents the sodium adduct of $[\mathrm{M}-18]^{+}$, or the loss of one water molecule. The sodium adduct of reduced FAX $\left([\mathrm{M}+\mathrm{Na}]^{+}\right.$ $m / z 483$ ) yielded one major and one minor daughter ion: $m / z$ 351 , representing the sodium adduct of the ion created after loss of the xylose unit, and $\mathrm{m} / z 465$, representing the sodium adduct of $[\mathrm{M}-18]^{+}$(loss of one water molecule). $\mathrm{MS}^{2}$ fragmentation of the sodium adduct of reduced FAXG $\left([\mathrm{M}+\mathrm{Na}]^{+} \mathrm{m} / z\right.$ 645) produced one major daughter ion: $m / z$ 483, representing the sodium adduct of the ion created after loss of the galactose unit.
Additionally, two minor daughter ions were observed: $m / z 627$, representing the sodium adduct of $[\mathrm{M}-18]^{+}$(loss of one water molecule) and $m / z 351$, representing the sodium adduct of the ion created after loss of both the galactose and xylose units.

\section{Application of Feruloylated Side-Chain Profiling Method to Cereal Grain Materials}

The contents of total esterified ferulic acid (as determined following alkaline hydrolysis with $2 \mathrm{M} \mathrm{NaOH}$ for $18 \mathrm{~h}$ ) of the insoluble fiber materials isolated from 12 cereal grains were in the range of about 2.3 (oats) to $33.0 \mathrm{mg} / \mathrm{g}$ insoluble fiber (grain maize; Table 2). To study the incorporation of ferulates into arabinoxylan side-chains the developed profiling approach was applied. Running plant cell wall samples required an SPE-C18 clean-up step. Without SPE-C18 clean-up, many hydrolysates formed gels during reduction, which possessed large foam-building capacities during the work-up step and rendered quantitative work very difficult. Following mildly acidic hydrolysis, SPE-18 clean-up, reduction, and LC-DAD/MS separation and detection, the quantitative distribution of the monomeric ferulates into unique feruloylated side-chain profiles was determined for each cereal grain and is shown in Table 3. FA was most abundantly liberated from all samples studied, with concentrations ranging between 4.97 (oats) and 100.23 (grain maize) $\mu \mathrm{mol} / \mathrm{g}$ insoluble fiber. FAX was found in all sample hydrolysates, too, but generally in lower concentrations than FA (Table 3). MS/MS fragmentation of the hydrolysates, together with retention time comparison with the FAXG standard compound allowed us to both confirm the existence of FAXG in all 12 cereal grains screened in this study and quantify this complex feruloylated side-chain in 10 out of 12 cereals (Table 3 ). For the majority of the cereals, over $70 \%$ of their total monomeric ferulates as determined by alkaline hydrolysis were quantitatively captured in their respective side-chain profiles, with values over $90 \%$ for several cereals (wheat, spelt, kamut, and wild rice). Values for proso millet, popcorn maize, and intermediate wheatgrass were lower, but still over $50 \%$. Although some free ferulic acid was observed in all TFA hydrolysates (see Figure 4), the quantities were small $(<10 \%)$ compared to the sum of ferulates captured with the screening method (see Table 3 ).

\section{DISCUSSION}

Feruloylated arabinoxylans are an essential structural component of the cell walls of grasses. Feruloylation and subsequent 

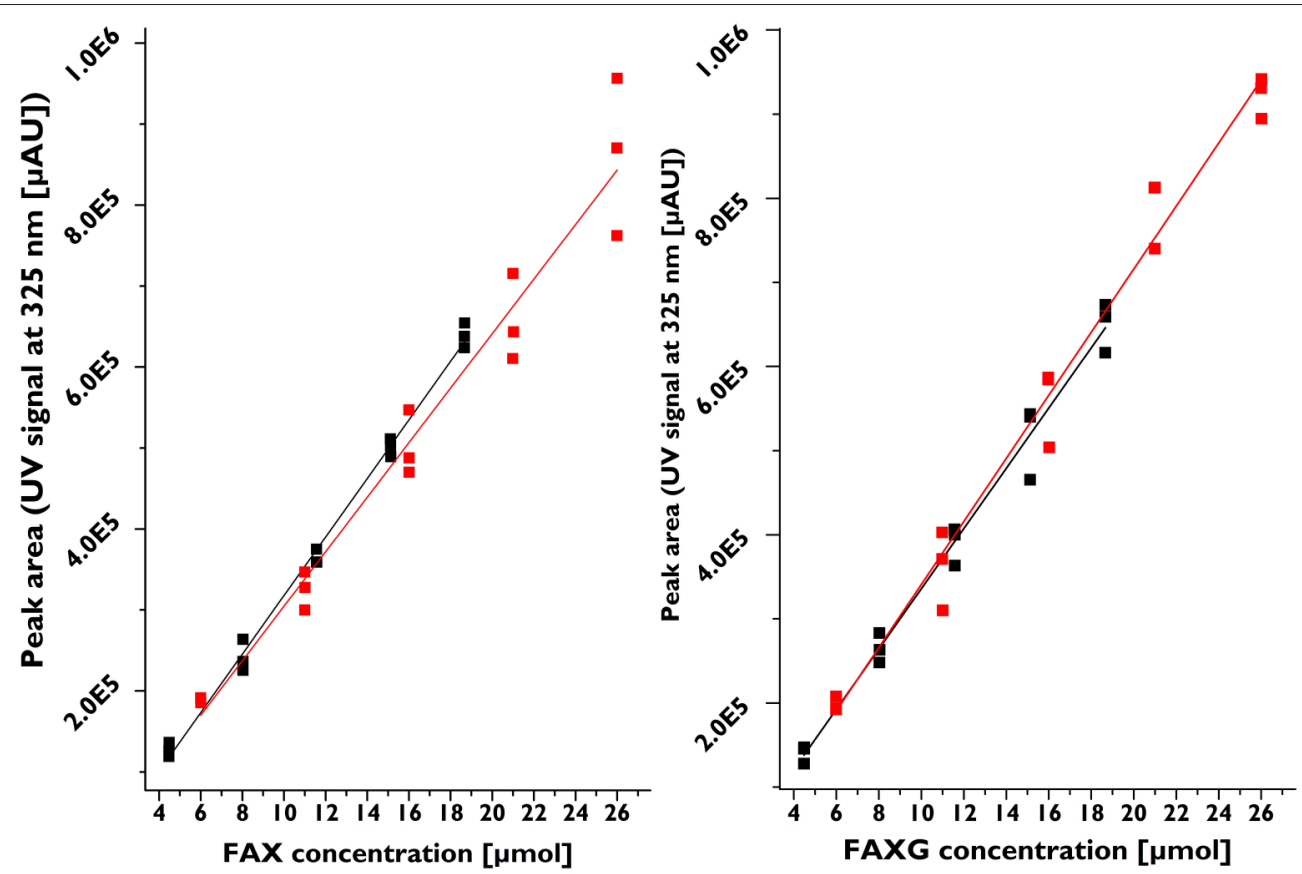

FIGURE 3 | Robustness of feruloylated side-chains quantification method as evidenced by linear correlation of six separate calibration curves prepared and analyzed four months apart. Each calibration curve was prepared from individual stock solutions. Black signals, first three calibration curves, concentration range 4.5-18.6 $\mu \mathrm{M}$; red signals, three calibration curves prepared four months later, concentration range 6.0-26.0 $\mu \mathrm{M}$. FAX,

$\beta$-D-xylopyranosyl-(1 $\rightarrow 2$ )-5-O-(trans-feruloyl)-L-arabinofuranose; FAXG, $\alpha$-L-galactopyranosyl-(1 $\rightarrow 2$ )- $\beta$-D-xylopyranosyl-(1 $\rightarrow 2$ )-5-O-trans-feruloyl-L-arabinofuranose.

TABLE 2 | Total ester-linked ferulic acid contents of insoluble grain fibers ${ }^{a}$.

\begin{tabular}{lcc}
\hline Grain & $\begin{array}{c}\text { Mean }(\boldsymbol{\mu} \mathbf{g} / \mathbf{g} \\
\text { insoluble fiber) }^{\mathbf{b}}\end{array}$ & $\begin{array}{c}\text { Standard deviation } \\
(\boldsymbol{\mu} \mathbf{g} / \mathbf{g} \text { insoluble fiber) }\end{array}$ \\
\hline Barley & 6895 & 242 \\
Grain maize & 33109 & 652 \\
Intermediate wheatgrass & 6672 & 43 \\
Kamut & 6141 & 105 \\
Long grain rice & 8991 & 241 \\
Oats & 2294 & 537 \\
Popcorn maize & 30117 & 456 \\
Proso millet & 9840 & 79 \\
Rye & 6240 & 178 \\
Spelt & 8799 & 408 \\
Wheat & 6925 & 510 \\
Wild rice & 2426 & 223
\end{tabular}

${ }^{a}$ Values determined via alkaline hydrolysis $(2 \mathrm{M} \mathrm{NaOH}, 18 \mathrm{~h}$, see Section Materials and Methods for additional details).

${ }^{b} n=3$; values corrected for residual protein and ash in the insoluble fiber material.

formation of ferulate oligomers was suggested to be an important factor in the regulation of cell wall extensibility (e.g., Azuma et al., 2005) and building first line defense mechanisms of the plant against invading pathogens (e.g., Santiago and Malvar, 2010). Feruloylated arabinoxylans form a substantial portion of the health-promoting dietary fiber complex in human diets containing whole grains, where they may produce both prebiotic and (potentially) antioxidative health benefits (Broekaert et al., 2011). Additionally, recalcitrance of biomaterials during lignocellulosic biofuel production and the digestibility of both stover and grain-based animal diets are substantially influenced by (di)feruloylated arabinoxylans. Mounting evidence points toward the possibility that feruloylated arabinoxylans' effects, particularly on enzymatic digestibility, are mediated not only by ferulate dimers/higher oligomers' crosslinking of cell wall polymers, but also by the degree and complexity of their monomeric feruloylated side-chain substituents. In isolated enzyme studies, many (but not all) arabinofuranosidases are unable to cleave feruloylated arabinose from the xylan backbone (Wood and McCrae, 1996; Luonteri et al., 1999; Remond et al., 2008). Structural characterization of feruloylated maize arabinoxylo-oligosaccharides resistant to mild acid pretreatment followed by enzymatic saccharification with an enzyme cocktail showed that most of these oligosaccharides contained the FAXG or FAX structural moiety (Appeldoorn et al., 2013). In addition, feruloylated oligosaccharides represented 39\% of the enzyme-resistant oligosaccharides. Yang et al. (2013) found differing short chain fatty acid profiles from in vitro fermentation with human fecal microbiota of autohydrolysates from wheat and maize brans and suggested that these differences may have been caused by the materials' divergent feruloylated side-chain profiles. Feruloylation of arabinoxylo-oligosaccharides limited their fermentability by human colon microbiota compared to non-feruloylated arabinoxylo-oligosaccharides (Snelders et al., 2014). In some contexts, such as lignocellulosic biofuel 
TABLE 3 | Application of the quantitative feruloylated side-chain profiling method to insoluble fibers from whole grains.

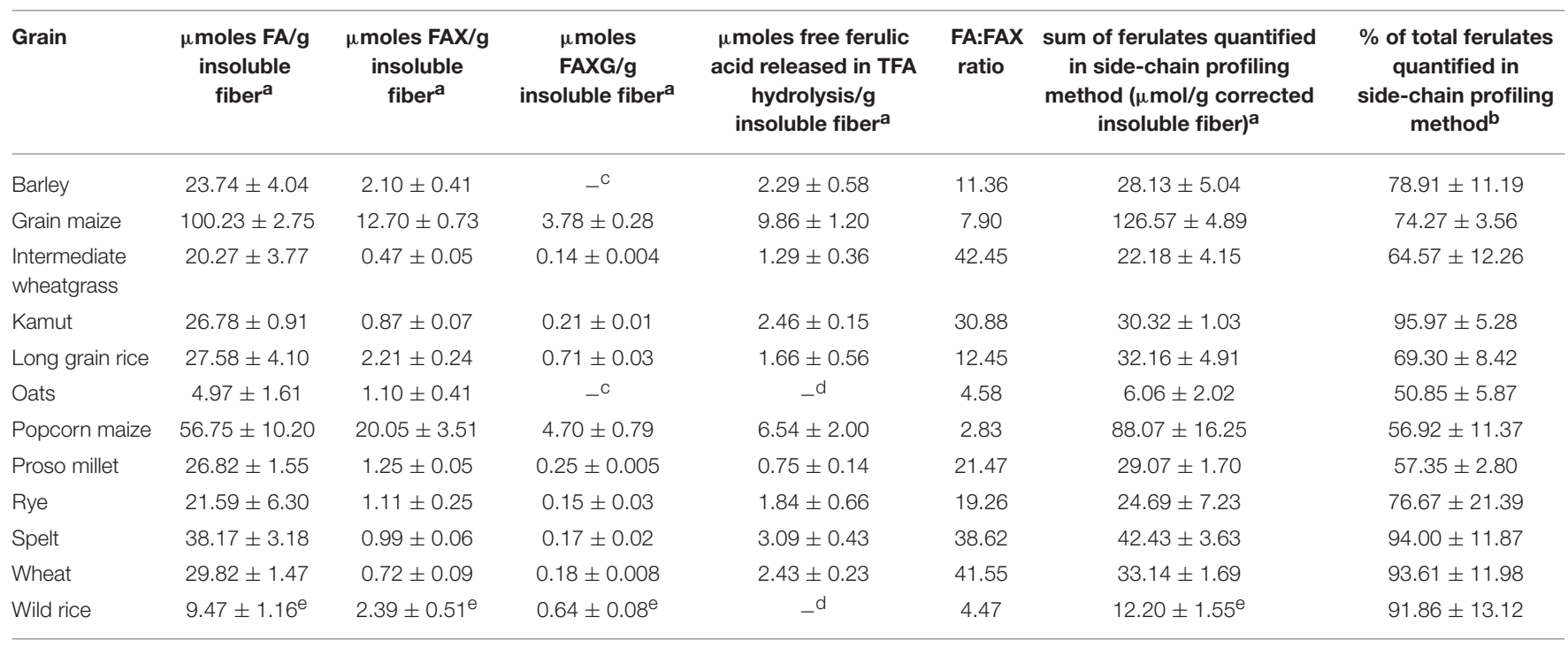

${ }^{a}$ Average \pm standard deviation from triplicate determinations, except where indicated. All values corrected for residual protein and ash.

${ }^{b}$ [(Sum of ferulates quantified from TFA hydrolysis/total ferulates as determined by alkaline hydrolysis $\left.) \times 100\right] \pm$ standard deviation.

${ }^{C}$ Detected, but could not be quantified due to co-elution with a matrix component.

${ }^{d}$ Detected, but not quantified due to low concentration

$e_{n}=2$.

FA, 5-O-trans-feruloyl-L-arabinofuranose; FAX, $\beta$-D-xylopyranosyl-(1 $\rightarrow 2)$-5-O-(trans-feruloyl)-L-arabinofuranose; FAXG, $\alpha$-L-galactopyranosyl-(1 $\rightarrow 2)-\beta$-D-xylopyranosyl-(1 $\rightarrow 2)$-5-Otrans-feruloyl-L-arabinofuranose.

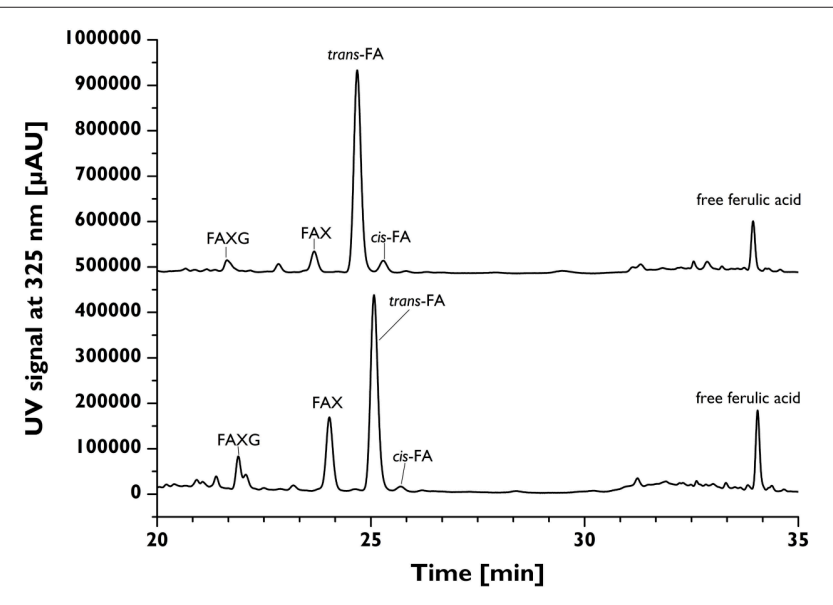

FIGURE 4 | Chromatographic separation of feruloylated side-chains and free ferulic acid in the TFA hydrolysates from insoluble long-grain rice (upper trace) and popcorn maize (lower trace) fibers following reduction. FA, 5-O-trans-feruloyl-L-arabinofuranose; FAX,

$\beta$-D-xylopyranosyl-(1 $\rightarrow 2)$-5-O-(trans-feruloyl)-L-arabinofuranose; FAXG $\alpha$-L-galactopyranosyl-( $1 \rightarrow 2)-\beta$-D-xylopyranosyl-( $1 \rightarrow 2)-5$-O-trans-feruloyl-Larabinofuranose; TFA, trifluoroacetic acid.

production, slower rates of enzymatic digestion or recalcitrance to digestion are an economical and processing drawback, although in other situations, this may be beneficial. For example, in fermentation of dietary fiber polysaccharides by the human gut microflora, a more slowly digestible arabinoxylan represents a potential delivery source of fermentable carbohydrates to the distal colon, which may be a boon to colon health.
Numerous methods for the determination of esterified ferulates in plant materials exist; however, only a few approaches aim to discriminate between different ferulate populations in plant materials and/or to localize the ferulates' position in cell wall polymers. Vaidyanathan and Bunzel (2012) presented a method capable of dividing a plant material's total monomeric ferulates into four populations: ester-linked to insoluble fibers, ester-linked to soluble fibers, ester-linked to oligosaccharides, and free ferulic acid. Philippe et al. (2007) created an elegant method for investigating local deposits of FA within the cell using a polyclonal antibody. Until now, however, a quantitative comparison of the feruloylated arabinoxylan side-chain profiles from varying plant cell wall sources has not been described. To date, information about ferulate incorporation into more complex arabinoxylan side-chains was merely based on NMR spectroscopic characterization of preparatively isolated feruloylated arabinoxylan fragments (e.g., Saulnier et al., 1995 and Allerdings et al., 2006), an approach that works well for plant materials rich in a specific structural element but is extremely laborious for plant materials low in a specific structural unit. Thus, we developed an efficient quantitative screening method for feruloylated sidechain substituents of arabinoxylans in plant cell walls following a mildly acidic hydrolysis, SPE-C18 clean-up, reduction, and LC-DAD/MS separation and detection. Although the method is not quantitative in the absolute sense (the reported side-chain concentrations should not be construed as the absolute total in the material, but rather the portion released under the hydrolysis conditions), the method offers the possibility for a quantitative comparison of feruloylated side-chain profiles in different cell wall materials. 
Quantitative liberation of feruloylated arabinoxylan sidechains is the major shortcoming of our approach. Enzymatic approaches are not feasible because the studied structural elements hinder enzymatic cleavage, as detailed above. Chemical approaches are often only semi-specific and need to be optimized for liberation versus destruction of specific building blocks of polymers. The mildly acidic hydrolysis method applied in our study was optimized earlier by Saulnier et al. (1995) for semi-specific release of feruloylated arabinoxylan side-chains and capitalizes on the greater acid lability of furanosidic compared to pyranosidic linkages. The recommended hydrolysis conditions $\left(50 \mathrm{mM} \mathrm{TFA}, 100^{\circ} \mathrm{C}, 2 \mathrm{~h}\right)$, which were used in this study, simultaneously balance the maximized cleavage of arabinofuranose-based side-chains with minimal degradation of ferulate ester bonds. However, the non-esterified ferulic acid detected in the hydrolysates (Table 3 ) is clearly a hydrolysis artifact, because any free ferulic acid naturally occurring in the plant materials is removed by washing steps at the end of the insoluble fiber isolation.

Keeping this limitation in mind, distinctive patterns were revealed in the cereals' profiles. Generally, the side-chain profiling method mirrored the total ferulate (alkaline hydrolysis) data: grains with higher total ferulate contents (for example, popcorn maize and grain maize) showed the highest concentration of side-chains and grains with lower total ferulate contents (such as oats and wild rice) produced the lowest concentration of sidechains. Interestingly, total side-chain concentration was not a direct predictor of the complexity of the side-chain profile, as determined by the FA:FAX ratio. For example, although oats' total feruloylated side-chain concentration was the lowest of the 12 grains screened in this study, its FA:FAX ratio was the thirdmost complex, topped only by wild rice and popcorn maize. The simplest side-chain profile was produced by intermediate wheat grass, a perennial grain already reported to possess simple, relatively unsubstituted arabinoxylans (Schendel et al., 2015). The three tested Triticum species (wheat, spelt, and kamut) clustered together with an extremely low level of side-chain complexity, producing FA:FAX ratios between 30 and 40. Additionally, the amount of total monomeric ferulates captured in their side-chain profiles was over $90 \%$, indicating that nearly all of the monomeric ferulates in these species are bound to arabinoxylans in the form of the simplest possible feruloylated side-chain, FA. The FA:FAX ratio of 2.83 from popcorn maize, on the other hand, represents a high level of side-chain complexity: every third feruloylated sidechain substituent in popcorn arabinoxylans is FAX. Compared to popcorn maize, grain maize had a larger concentration of total side-chains, but a simpler complexity profile. Barley and long grain rice produced similar profiles, with moderate levels of both FA and FAX. As already mentioned, oats, but also wild rice, resulted in the surprising profiles of low absolute total sidechain levels, but high relative values of side-chain complexity. Another surprising result of our screening was the discovery of low levels of FAXG, which had previously only been described in maize (Allerdings et al., 2006), in all tested cereals. Although the sheer quantity of FAXG in maize grain cell walls is clearly higher than in other cereals, its biosynthesis in grain cell walls appears to be ubiquitous throughout the Poaceae family.

For most of the screened cereals, the side-chain profiling method quantified more than $70 \%$ of their total ester-linked monomeric ferulate populations, with intermediate wheatgrass, oats, popcorn maize, and proso millet standing as exceptions. It is possible that biosynthesis in these cereals directs a larger portion of alkali-hydrolysable monomeric ferulates into other structural depots resistant to the mild TFA hydrolysis conditions in this study, such as ester-linked to lignin or other polyphenolic or polyaliphatic compounds such suberin-type polymers. Twodimensional NMR analysis of the residues remaining after TFA hydrolysis could serve as a starting point for investigating this possibility.

Another aspect that needs to be studied in future is whether or not the complexity of the feruloylated side-chains has an impact on peroxidase- and laccase-mediated diferulate formation. It can be hypothesized that simple feruloylated side-chains are more heavily involved in cross-link formation than sterically complex, hindered feruloylated arabinoxylan side-chains.

\section{CONCLUSION}

The developed method enables the quantitative comparison of feruloylated side-chain profiles between different cell wall materials, opening new possibilities for determining arabinoxylan structure-function relationships in the future. We found that feruloylated arabinoxylans from cereal grains differed substantially from each other in some aspects, such as FA:FAX ratio. We also confirmed the presence of FAXG in all tested grains.

\section{AUTHOR CONTRIBUTIONS}

$\mathrm{MB}$ and RS designed the research, RS and MM conducted the experiments, RS and MM analyzed the data results. RS and MB wrote the manuscript. All authors read and approved the final manuscript.

\section{ACKNOWLEDGMENTS}

The authors thank Pepe Schrimpf for his assistance with isolation of insoluble fiber materials and standard compounds and Ute Schmitt for her help with preparative clean-up of standard compounds. We acknowledge support from the Deutsche Forschungsgemeinschaft and Open Access Publishing Fund of Karlsruhe Institute of Technology.

\section{SUPPLEMENTARY MATERIAL}

The Supplementary Material for this article can be found online at: http://journal.frontiersin.org/article/10.3389/fpls.2015. 01249 


\section{REFERENCES}

Allerdings, E., Ralph, J., Schatz, P. F., Gniechwitz, D., Steinhart, H., and Bunzel, M. (2005). Isolation and structural identification of diarabinosyl 8-O-4dehydrodiferulate from maize bran insoluble fibre. Phytochemistry 66, 113-124. doi: 10.1016/j.phytochem.2004.10.026

Allerdings, E., Ralph, J., Steinhart, H., and Bunzel, M. (2006). Isolation and structural identification of complex feruloylated heteroxylan side-chains from maize bran. Phytochemistry 67, 1276-1286. doi: 10.1016/j.phytochem.2006.04.018

Appeldoorn, M. M., de Waard, P., Kabel, M. A., Gruppen, H., and Schols, H. A. (2013). Enzyme resistant feruloylated xylooligomer analogues from thermochemically treated corn fiber contain large side chains, ethyl glycosides and novel sites of acetylation. Carbohydr. Res. 381, 33-42. doi: 10.1016/j.carres.2013.08.024

Appeldoorn, M. M., Kabel, M. A., Van Eylen, D., Gruppen, H., and Schols, H. A. (2010). Characterization of oligomeric xylan structures from corn fiber resistant to pretreatment and simultaneous saccharification and fermentation. J. Agric. Food Chem. 58, 11294-11301. doi: 10.1021/jf102849x

Azuma, T., Okita, N., Nanmori, T., and Yasuda, T. (2005). Relationship between the deposition of phenolic acids in the cell walls and the cessation of rapid growth in internodes of floating rice. Plant Prod. Sci. 8, 447-453. doi: 10.1626/pps.8.447

Broekaert, W. F., Courtin, C. M., Verbeke, K., Van de Wiele, T., Verstraete, W., and Delcour, J. A. (2011). Prebiotic and other health-related effects of cereal-derived arabinoxylans, arabinoxylan-oligosaccharides, and xylooligosaccharides. Crit. Rev. Food Sci. Nutr. 51, 178-194. doi: 10.1080/10408390903044768

Bunzel, M. (2001). Monomere und Dimere Phenolcarbonsäuren als Strukturbildende Elemente in Löslichen und Unlöslichen Getreideballaststoffen. Ph.D. thesis, Universität Hamburg.

Bunzel, M., Allerdings, E., Ralph, J., and Steinhart, H. (2008). Cross-linking of arabinoxylans via 8-8-coupled diferulates as demonstrated by isolation and identification of diarabinosyl 8-8(cyclic)-dehydrodiferulate from maize bran. J. Cereal Sci. 47, 29-40. doi: 10.1016/j.jcs.2006.12.005

Bunzel, M., Allerdings, E., Sinnwell, V., Ralph, J., and Steinhart, H. (2002). Cell wall hydroxycinnamates in wild rice (Zizania aquatica L.) insoluble dietary fibre. Eur. Food Res. Technol. 214, 482-488. doi: 10.1007/s00217-002-0512-3

Bunzel, M., Ralph, J., Marita, J. M., Hatfield, R. D., and Steinhart, H. (2001). Diferulates as structural components in soluble and insoluble cereal dietary fibre. J. Sci. Food Agric. 81, 653-660. doi: 10.1002/jsfa.861

Chundawat, S. P. S., Beckham, G. T., Himmel, M. E., and Dale, B. E. (2011). Deconstruction of lignocellulosic biomass to fuels and chemicals. Annu. Rev. Chem. Biomol. Eng. 2, 121-145. doi: 10.1146/annurev-chembioeng-061010114205

de O Buanafina, M. M. (2009). Feruloylation in grasses: current and future perspectives. Mol. Plant 2, 861-872. doi: 10.1093/mp/ssp067

de O Buanafina, M. M., and Fescemyer, H. W. (2012). Modification of esterified cell wall phenolics increases vulnerability of tall fescue to herbivory by the fall armyworm. Planta 236, 513-523. doi: 10.1007/s00425-012-1625-y

de Vries, S., Pustjens, A. M., van Rooijen, C., Kabel, M. A., Hendriks, W. H., and Gerrits, W. J. J. (2014). Effects of acid extrusion on the degradability of maize distillers dried grain with solubles in pigs. J. Anim. Sci. 92, 5496-5506. doi: 10.2527/jas.2014-7596

Dobberstein, D., and Bunzel, M. (2010). Separation and detection of cell wallbound ferulic acid dehydrodimers and dehydrotrimers in cereals and other plant materials by reversed phase high-performance liquid chromatography with ultraviolet detection. J. Agric. Food Chem. 58, 8927-8935. doi: $10.1021 /$ jf101514j

Gottlieb, H. E., Kotlyar, V., and Nudelman, A. (1997). NMR chemical shifts of common laboratory solvents as trace impurities. J. Org. Chem. 62, 7512-7515. doi: $10.1021 /$ jo971176v

Grabber, J. H., Hatfield, R. D., and Ralph, J. (1998). Diferulate cross-links impede the enzymatic degradation of non-lignified maize walls. J. Sci. Food Agric. 77, 193-200.

Harris, P. J., and Trethewey, J. A. K. (2010). The distribution of ester-linked ferulic acid in the cell walls of angiosperms. Phytochem. Rev. 9, 19-33. doi: 10.1007/s11101-009-9146-4

Huisman, M. M. H., Schols, H. A., and Voragen, A. G. J. (2000). Glucuronoarabinoxylans from maize kernel cell walls are more complex than those from sorghum kernel cell walls. Carbohydr. Polym. 43, 269-279. doi: 10.1016/S0144-8617(00)00154-5

Jung, H.-J. G., Samac, D. A., and Sarath, G. (2012). Modifying crops to increase cell wall digestibility. Plant Sci. 185-186, 65-77. doi: 10.1016/j.plantsci.2011. 10.014

Kabel, M. A., Carvalheiro, F., Garrote, G., Avgerinos, E., Koukios, E., Parajó, J. C., et al. (2002). Hydrothermally treated xylan rich by-products yield different classes of xylo-oligosaccharides. Carbohydr. Polym. 50, 47-56. doi: 10.1016/S0144-8617(02)00045-0

Kamisaka, S., Takeda, S., Takahashi, K., and Shibata, K. (1990). Diferulic and ferulic acid in the cell-wall of Avena coleoptiles - their relationships to mechanical properties of the cell-wall. Physiol. Plant. 78, 1-7. doi: 10.1111/j.13993054.1990.tb08706.x

Luonteri, E., Kroon, P. A., Tenkanen, M., Teleman, A., and Williamson, G. (1999). Activity of an Aspergillus terreus $\alpha$-arabinofuranosidase on phenolicsubstituted oligosaccharides. J. Biotechnol. 67, 41-48. doi: 10.1016/s01681656(98)00164-3

Philippe, S., Tranquet, O., Utille, J.-P., Saulnier, L., and Guillon, F. (2007). Investigation of ferulate deposition in endosperm cell walls of mature and developing wheat grains by using a polyclonal antibody. Planta 225, 1287-1299. doi: 10.1007/s00425-006-0422-x

Ralph, J., Grabber, J. H., and Hatfield, R. D. (1995). Lignin-ferulate crosslinks in grasses: active incorporation of ferulate polysaccharide esters into ryegrass lignins. Carbohydr. Res. 275, 167-178. doi: 10.1016/0008-6215(95) 00237-N

Ralph, J., Quideau, S., Grabber, J. H., and Hatfield, R. D. (1994). Identification and synthesis of new ferulic acid dehydrodimers present in grass cell walls. J. Chem. Soc. Perkin Trans. 1, 3485-3498. doi: 10.1039/p19940003485

Remond, C., Boukari, T., Chambat, G., and O'Donohue, M. (2008). Action of a GH $51 \alpha$-L-arabinofuranosidase on wheat-derived arabinoxylans and arabino-xylooligosaccharides. Carbohydr. Polym. 72, 424-430. doi: 10.1016/j.carbpol.2007.09.008

Santiago, R., and Malvar, R. A. (2010). Role of dehydrodiferulates in maize resistance to pests and diseases. Int. J. Mol. Sci. 11, 691-703. doi: 10.3390/ijms11020691

Saulnier, L., Crepeau, M. J., Lahaye, M., Thibault, J. F., Garcia-Conesa, M. T., Kroon, P. A., et al. (1999). Isolation and structural determination of two 5,5'-diferuloyl oligosaccharides indicate that maize heteroxylans are covalently cross-linked by oxidatively coupled ferulates. Carbohydr. Res. 320, 82-92. doi: 10.1016/S0008-6215(99)00152-4

Saulnier, L., Vigouroux, J., and Thibault, J.-F. (1995). Isolation and partial characterization of feruloylated oligosaccharides from maize bran. Carbohydr. Res. 272, 241-253. doi: 10.1016/0008-6215(95)00053-V

Schendel, R. R., Becker, A., Tyl, C. E., and Bunzel, M. (2015). Isolation and characterization of feruloylated arabinoxylan oligosaccharides from the perennial cereal grain intermediate wheat grass (Thinopyrum intermedium). Carbohydr. Res. 407, 16-25. doi: 10.1016/j.carres.2015.01.006

Snelders, J., Olaerts, H., Dornez, E., Van de Wiele, T., Aura, A.-M., Vanhaecke, L., et al. (2014). Structural features and feruloylation modulate the fermentability and evolution of antioxidant properties of arabinoxylanoligosaccharides during in vitro fermentation by human gut derived microbiota. J. Funct. Foods 10, 1-12. doi: 10.1016/j.jff.2014.05.011

Steinhart, H., and Bunzel, M. (2003). Separation techniques in structural analysis of dietary fiber polysaccharides. Chromatographia 57(Suppl.), S359-S361. doi: 10.1007/BF02492129

Vaidyanathan, S., and Bunzel, M. (2012). Development and application of a methodology to determine free ferulic acid and ferulic acid ester-linked to different types of carbohydrates in cereal products. Cereal Chem. 89, 247-254. doi: 10.1094/CCHEM-02-12-0013-R

Verbruggen, M. A., Beldman, G., and Voragen, A. G. J. (1995). The selective extraction of glucuronoarabinoxylans from sorghum endosperm cell walls using barium and potassium hydroxide solutions. J. Cereal Sci. 21, 271-282. doi: 10.1006/jcrs.1995.0030

Vogel, J. (2008). Unique aspects of the grass cell wall. Curr. Opin. Plant Biol. 11, 301-307. doi: 10.1016/j.pbi.2008.03.002

Wende, G., and Fry, S. C. (1997). 2-O- $\beta$-D-xylopyranosyl-(5-O-feruloyl)-Larabinose, a widespread component of grass cell walls. Phytochemistry 44, 1019-1030. doi: 10.1016/S0031-9422(96)00649-8 
Willis, R. B., Montgomery, M. E., and Allen, P. R. (1996). Improved method for manual, colorimetric determination of total Kjeldahl nitrogen using salicylate. J. Agric. Food Chem. 44, 1804-1807. doi: 10.1021/jf950522b

Wood, T. M., and McCrae, S. I. (1996). Arabinoxylan-degrading enzyme system of the fungus Aspergillus awamori: purification and properties of an $\alpha$-L-arabinofuranosidase. Appl. Microbiol. Biotechnol. 45, 538-545. doi: $10.1007 / \mathrm{s} 002530050725$

Yang, J.-G., Maldonado-Gómez, M. X., Hutkins, R. W., and Rose, D. J. (2013). Production and in vitro fermentation of soluble, non-digestible, feruloylated oligo- and polysaccharides from maize and wheat brans. J. Agric. Food Chem. 62, 159-166. doi: 10.1021/jf404305y
Conflict of Interest Statement: The authors declare that the research was conducted in the absence of any commercial or financial relationships that could be construed as a potential conflict of interest.

Copyright (C) 2016 Schendel, Meyer and Bunzel. This is an open-access article distributed under the terms of the Creative Commons Attribution License (CC $B Y)$. The use, distribution or reproduction in other forums is permitted, provided the original author(s) or licensor are credited and that the original publication in this journal is cited, in accordance with accepted academic practice. No use, distribution or reproduction is permitted which does not comply with these terms. 